\title{
Arborização urbana no Brasil: um reflexo de injustiça ambiental
}

\section{Arbolado urbano en Brasil: un reflejo de la injusticia ambiental}

\section{Urban Afforestation in Brazil: a Reflection of Environmental Injustice}

Taise Ernestina Prestes Nogueira Duarte taisepduarte@hotmail.com Universidade Federal de Mato Grosso, UFMT- Câmpus de Rondonópolis, MT

Fabio Angeoletto fabio_angeoletto@yahoo.es Universidade Federal de Mato Grosso, UFMT - Câmpus de Rondonópolis, MT

Enrique Richard chelonos@gmail.com Universidad Mayor de San Andrés, La Paz, Bolívia

Marcelo Caetano Vacchiano marcelo.vacchiano@hotmail.com Universidade Federal de Mato Grosso, UFMT-Câmpus de Rondonópolis, MT

Deleon da Silva Leandro deleon_roo@hotmail.com Universidade Federal de Mato Grosso, UFMT-Câmpus de Rondonópolis, MT

João Fernando Copetti Bohrer jf.bohrer@hotmail.com Universidade Federal de Mato Grosso, UFMT-Câmpus de Rondonópolis, MT

Leandro Bernardo Leite leandronago@hotmail.com Universidade Federal de Mato Grosso, UFMT-Câmpus de Rondonópolis, MT 
Resumo: O presente artigo tem como objetivo traçar um panorama da arborização urbana no Brasil a partir dos dados da presença de árvores no entorno das residências do Censo 2010 disponibilizadas pelo IBGE. Buscamos discutir as dinâmicas envolvidas neste panorama. Estes dados são de suma importância para auxiliar na compreensão da realidade atual em que se encontra a arborização urbana em cada região do país e a partir desta compreensão abrir portas para novas iniciativas voltadas para a melhoria da qualidade ambiental urbana e dos serviços ambientais correspondentes. A análise dos dados revelou uma relação positiva entre planejamento urbano e arborização urbana. Ademais, detectamos que os municípios menores obtiveram maiores percentuais de arborização comparados às cidades grandes e médias.

Palavras-chave: cobertura vegetal, qualidade ambiental, planejamento urbano, biodiversidade urbana, segregação socioespacial.

Resumen: En este artículo presentamos una visión general del arbolado urbano en Brasil a partir de los datos acerca de los árboles cercanos a las viviendas del Censo de 2010 publicado por el IBGE. Tratamos de analizar las dinámicas implicadas en este panorama. Estos datos se vuelven muy importantes para ayudar a comprender la realidad actual del arbolado urbano en las distintas regiones del país y desde esta comprensión, abrir puertas a nuevas iniciativas con el reto de mejorar la calidad del medio ambiente urbano y de los servicios ambientales involucrados. El análisis de datos reveló una relación positiva entre la planificación urbana y el arbolado urbano. Además, hemos detectado que las ciudades más pequeñas tuvieron un mayor porcentaje de arbolado en comparación con ciudades grandes y medianas.

Palabras clave: cubierta vegetal, la calidad del medio ambiente, la planificación urbana, la biodiversidad urbana, segregación socio-espacial.

\begin{abstract}
The objective of this paper is to draw broad view of the urban afforestation in Brazil, since the data of the trees around the households from of the Census 2010, made available by IBGE. We try to analyze the dynamics involved in this scenario. These data become very important to help understand the current reality of urban trees in different regions of the country and from these, open doors to new initiatives with the challenge of improving the quality of the urban environment and the environmental services involved. Our data analysis has revealed a positive relationship between urban planning and urban trees. In addition, we've found that smaller cities had a higher percentage of trees compared to large and medium cities.
\end{abstract}

Key-Words: Plant cover, Environmental quality, Urban planning, Urban biodiversity, Socio-spatial segregation.

\title{
INTRODUÇÃO
}

De acordo com a EMBRAPA (2002), a arborização urbana pode ser compreendida como toda a cobertura vegetal de porte arbóreo existente nas cidades, compreendendo as áreas livres de uso público e potencialmente coletivas, áreas livres particulares e acompanhamento do sistema viário. Portanto, o conceito de arborização urbana inclui a cobertura vegetal urbana de porte arbóreo, natural ou cultivada.

A importância da cobertura vegetal urbana se dá em função dos serviços ecossistêmicos que ela desempenha, capazes de aumentar a biodiversidade, melhorar a qualidade do 
ar, diminuir os riscos de inundações, proporcionar maior conforto térmico, diminuir a utilização de climatização artificial, proporcionar consequências positivas a saúde humana e consequentemente melhorar a qualidade de vida nas áreas urbanas (NUCCI; CAVALHEIRO, 1999; SAMPAIO, 2006; DUARTE et al., 2008; TIAN; TAO; SHI, 2011; ALVES, 2012; SECRETARIAT OF THE CONVENTION ON BIOLOGICAL DIVERSITY, 2012; LOCKE et al., 2013; RAHMAN, ARMSON; ENNOS, 2014; CUBINO; LOZANO; SUBIRÓS, 2015; ALBUQUERQUE; LOPES, 2016; LOURENÇO et al., 2016, RICHARD; CONTRERAS; ANGEOLETTO, 2017).

O crescente processo de urbanização registrado ao redor de todo o globo apresenta diversas consequências negativas do ponto de vista ambiental. As consequências negativas da urbanização estão relacionadas ao aumento da impermeabilização do solo, supressão de vegetação nativa, aumento da poluição do ar pela queima de combustíveis fósseis, aumento no consumo de energia, aumento dos riscos de enchentes e inundações e consequentemente, perdas na qualidade ambiental urbana.

Atualmente, estima-se que o Brasil possua um índice de população urbana superior ao registrado no mundo e na América Latina. O índice de população urbana mundial é de 67\%, enquanto na América Latina representa cerca de 80\%. Já no Brasil este índice chega a 83\% (SECRETARIAT OF THE CONVENTION ON BIOLOGICAL DIVERSITY, 2012; ANGEOLETTO et al., 2016; CRETELLA; BUENGER, 2016).

Tendo em vista os altos índices de expansão urbana presenciados no Brasil nas últimas décadas, é prioritário criar alternativas que propiciem que este crescimento ocorra de forma mais sustentável, representando um menor prejuízo à qualidade ambiental e consequentemente à qualidade de vida urbana. Portanto, os serviços ecossistêmicos da arborização urbana podem ser utilizados como forma de compensação da perda de qualidade ambiental ocorrida no processo de produção do espaço.

Incrementar a arborização urbana no Brasil ainda pode ser considerado um desafio a ser superado, visto que a implantação de arborização de vias públicas só começou a popularizar-se a partir da segunda metade do século XIX (VIGNOLA JUNIOR, 2015). Tendo em vista, que a arborização urbana é uma prática relativamente nova no Brasil, sua implantação geralmente ocorre de forma empírica, fora de um contexto técnico-científico na maior parte das cidades brasileiras (SILVA, 2013).

A falta de iniciativas voltadas a orientar o incremento da arborização urbana, planejada de acordo com os serviços ecossistêmicos desejados, adaptada às especificidades locais e necessidades atuais, faz com que a arborização urbana ainda seja vista como um elemento meramente estético na paisagem urbana. Entretanto, para se chegar a estes objetivos é necessário uma maior compreensão sobre as realidades locais para a elaboração de propostas adaptadas à estas realidades.

A partir do último Censo Demográfico, o IBGE (2010a) passou a pesquisar algumas características do entorno das residências, dentre elas a arborização urbana. Estes dados são de suma importância para auxiliar na compreensão da realidade atual da arborização urbana em cada região do país, e a partir desta compreensão refletir sobre as oportunidades relativas à melhoria da qualidade ambiental urbana. Neste contexto, o presente artigo tem 
como objetivo traçar um panorama da arborização urbana no Brasil a partir dos dados da arborização no entorno das residências do Censo 2010, buscando discutir as dinâmicas envolvidas.

\section{ANÁLISE DOS DADOS SOBRE ARBORIZAÇÃO URBANA NO BRASIL}

A coleta de dados sobre a arborização no entorno do domicílio no Censo IBGE 2010 é a primeira iniciativa desta magnitude, voltada ao conhecimento da flora urbana no Brasil, permitindo uma maior compreensão da realidade da arborização urbana no país. Nesse sentido, os maiores percentuais na região Sudeste com $73,5 \%$, seguido pela região Sul, com $72,1 \%$, Centro Oeste com $69,5 \%$, Nordeste com $61,5 \%$ e a região Norte com o menor índice registrado, 36,7\% (Gráfico 1).

Gráfico 1: Percentual de arborização urbana por região.

\section{Percentual de arborização por região}

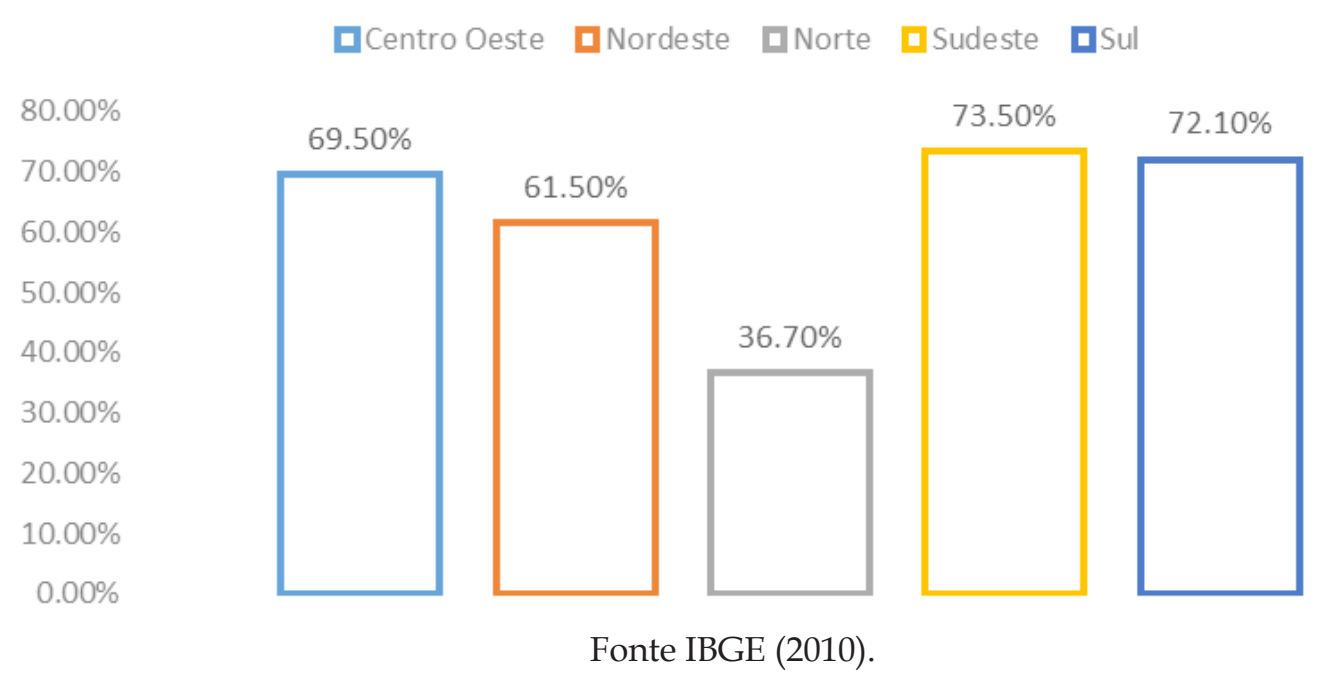

Da mesma forma que inexistem estudos relacionados a arborização urbana no Brasil, que englobem todo o território nacional, raras iniciativas tem se dedicado ao conhecimento da flora urbana nas regiões Centro-Oeste, Norte e Nordeste. Em virtude disto, ainda não há uma profunda compreensão sobre os fatores responsáveis pela diferença entre os percentuais de arborização no entorno dos domicílios obtidos entre as regiões brasileiras.

Com relação ao tamanho do município, verificou-se que as cidades menores, com população até 20.000 habitantes obtiveram o maior percentual de arborização urbana $(70,6 \%)$, registrando uma gradativa redução conforme o crescimento da população. As cidades médias com população entre 100.001 e 200.000 têm o menor percentual (65,4\%). Já as cidades médias com população entre 200.001 e 500.000 possuem um percentual de arborização levemente maior (68,9\%). As cidades grandes registraram percentuais de $67 \%$ (Gráfico 2). 
Gráfico 2: Percentual de arborização de acordo com o tamanho do município.

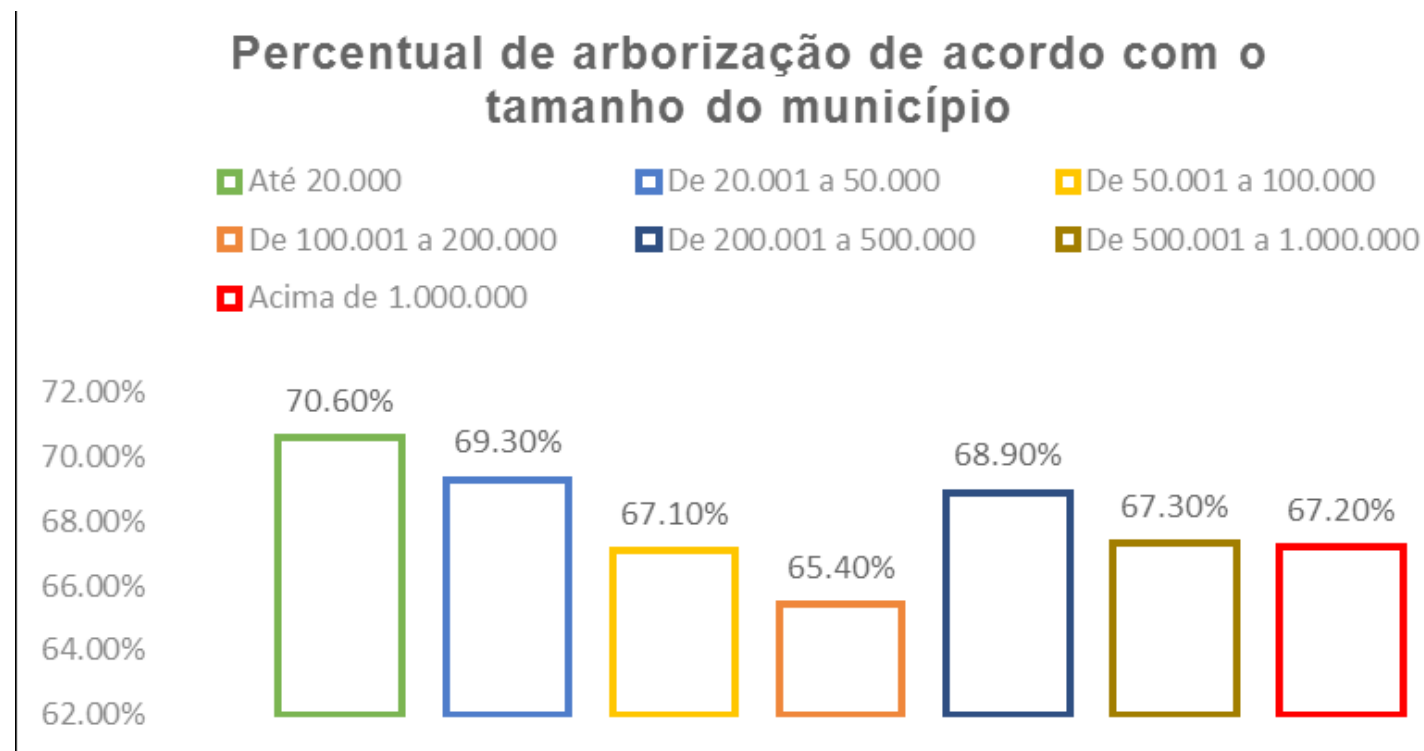

Fonte: IBEG (2010).

As cidades médias no Brasil têm experimentado altos índices de crescimento populacional e econômico, contribuindo significativamente para a expansão e o adensamento da rede urbana no Brasil. Em 2007, as cidades médias concentravam 25,1\% da população, contribuindo com $27,4 \%$ do PIB nacional, apresentando médias de crescimento populacional anual em torno de $2 \%$ e um aumento do PIB acima dos $5 \%$ ao ano (IPEA, 2008). Muito embora os índices de crescimento das cidades médias brasileiras sejam vistos com otimismo, Maricato (2011) reflete que a aceleração extraordinária do crescimento das cidades de médio porte, de modo geral exige maior atenção devido às consequências socioambientais decorrentes da velocidade do processo de urbanização. Tais consequências são fruto da falta de planejamento público voltado para a expansão urbana, visto que, na maioria das cidades médias, o planejamento das ações públicas não acompanha as demandas populacionais.

Para o IPEA (2008), a falta de planejamento das ações públicas e privadas são as marcas deletérias da exclusão e da segregação socioespacial. Do ponto de vista ambiental, o rápido processo de urbanização exerce forte pressão sobre a cobertura vegetal, onde o acesso à mesma tornou-se instrumento de valorização fundiária e, portanto, de segregação socioespacial.

De acordo com as tendências de crescimento urbano esperadas para as cidades médias no Brasil, bem como o agravamento da qualidade ambiental urbana como consequências negativas decorrentes do rápido processo de urbanização, o planejamento da arborização urbana torna-se ainda mais importante. Neste panorama, Angeoletto et al. (2015) propõem o estabelecimento de políticas ambientais urbanas mais exitosas na proteção da biodiversidade e no incremento da qualidade de vida da população urbana nas cidades médias no Brasil.

Com relação às cidades com mais de 1.000.000 habitantes, os dados relativos à arborização no entorno do domicílio, disponibilizado pelo IBGE (2010b) apontam a cidade de Goiânia na região Centro-Oeste com o maior percentual registrado (89,5\%), seguida por demais cidades da região Sul e Sudeste, com exceção de Fortaleza, com percentuais variando entre $88,4 \%$ 
e $72,2 \%$. Já os menores percentuais encontrados (entre $60,8 \%$ e $22,4 \%$ ) se concentraram nas regiões Norte e Nordeste, com exceção de Brasília, na região Centro-Oeste (Tab. 1).

Tabela 1: Percentual de arborização nas cidades com mais de 1.000 .000 de habitantes.

\begin{tabular}{c|c|c|c}
\hline \multirow{2}{*}{ PERCENTUAL DE ARBORIZAÇÃO NAS CIDADES COM MAIS DE 1.000.000 DE HABITANTES } \\
\hline Colocação & Cidade & $\begin{array}{c}\text { Percentual de arborização } \\
\text { no entorno do domicilio }\end{array}$ & Região \\
\hline $1^{\text {a }}$ & Goiânia & $89,50 \%$ & Centro Oeste \\
\hline $2^{\text {a }}$ & Campinas & $88,40 \%$ & Sudeste \\
\hline $3^{\text {a }}$ & Belo Horizonte & $88,40 \%$ & Sudeste \\
\hline $4^{\text {a }}$ & Porto Alegre & $83 \%$ & Sul \\
\hline $5^{\text {a }}$ & Curitiba & $82,90 \%$ & Sul \\
\hline $6^{\text {a }}$ & São Paulo & $76,40 \%$ & Sudeste \\
\hline $7^{\text {a }}$ & Fortaleza & $75,40 \%$ & Sudeste \\
\hline $8^{\text {a }}$ & Guarulhos & $72,40 \%$ & Sudeste \\
\hline $9^{\text {a }}$ & Rio de Janeiro & $72,20 \%$ & Nordeste \\
\hline $10^{\text {a }}$ & Recife & $60,08 \%$ & Nordeste \\
\hline $11^{\text {a }}$ & Salvador & $40 \%$ & Centro Oeste \\
\hline $12^{\text {a }}$ & Brasília & $37,20 \%$ & Nordeste \\
\hline $13^{\text {a }}$ & São Luiz & $32,70 \%$ & Norte \\
\hline $14^{\text {a }}$ & Manaus & $25,10 \%$ & Norte \\
\hline $15^{\text {a }}$ & Belém & $22,40 \%$ & \\
\hline
\end{tabular}

Fonte: IBGE (2010b).

A cidade de Goiânia foi projetada pelo urbanista Atílio Corrêa Lima em 1933, inspirada no conceito de cidades-jardins de Ebenezer Howard. Dentre características do projeto urbanístico de cidades-jardins em Goiânia estão as áreas livres como o Parque dos Buritis (40 hectares), o Parque Botafogo (54 hectares) e Paineira (16 hectares), praças amplas e jardins num total de 162 hectares destinados ao lazer e recreação. Além dos espaços livres, os cruzamentos bem arborizados e os jardins nas principais avenidas foram previamente projetados para climatização da cidade (CURADO, 2014). Portanto, o alto percentual de arborização urbana na cidade de Goiânia é fruto do investimento em infraestrutura urbana planejada para acolher o verde urbano e proporcionar qualidade ambiental.

Dentre as grandes cidades com maior percentual de arborização no entorno do domicílio, destacaram-se cidades da região Sul e Sudeste - Campinas, Belo Horizonte, Porto Alegre, Curitiba e São Paulo. Apenas a cidade de Fortaleza figura entre as grandes cidades da Região Nordeste.

Os percentuais de arborização urbana mais alarmantes correspondem a Manaus e Belém (25,1\% e 22,4\% respectivamente), duas cidades pertencentes à Amazônia brasileira. De acordo com Pereira e Vieira (2016), atualmente a Amazônia brasileira concentra cerca de 25 milhões de habitantes, na sua maioria $(72,6 \%)$ vivendo em áreas urbanas. Este percentual segue aumentando devido aos fluxos migratórios intra-regionais do campo para as cidades e dos grandes centros para as cidades médias. 
Muito embora os estudos voltados a região amazônica estejam mais atrelados as questões referentes às áreas exteriores à cidade, o modo com que o processo de expansão urbana ocorre na Amazônia tem acentuado ainda mais os problemas socioambientais existentes (BECKER, 2013; PEREIRA; VIEIRA, 2016). Neste contexto, a biodiversidade urbana na Amazônia brasileira ainda é um campo inexplorado.

De acordo com o IBGE (2010a) a região metropolitana de Belém (segunda mais populosa da Amazônia), apesar de possuir um território correspondente a um pouco menos de $1 \%$ do estado do Pará, concentra $1 / 3$ de toda a população do estado. Apesar de constituir-se como uma centro econômico, a desigualdade socioespacial na cidade de Belém concentra a infraestrutura urbana nos centros econômicos, enquanto que as áreas periféricas apresentam características rurais com habitações irregulares e geralmente autoconstruídas (PADOCH et al., 2008; PEREIRA; VIEIRA, 2016).

O baixo percentual de arborização no entorno dos domicílios, apontado pelo IBGE (2010b) em Manaus e Belém, podem estar relacionados à falta de infraestrutura urbana presente nestas cidades. O Mobilize Brasil (2012) realizou uma pesquisa sobre a qualidade das calçadas em 39 cidades do Brasil, elegendo alguns critérios, dentre eles, a arborização. Como resultado desta pesquisa, o Mobilize Brasil apontou que, no geral, todas as cidades pesquisadas são mal arborizadas. Ademais, a qualidade das calçadas não favorece a arborização.

Figura 1: Calçadas em Manaus - AM não favorecem a arborização urbana.

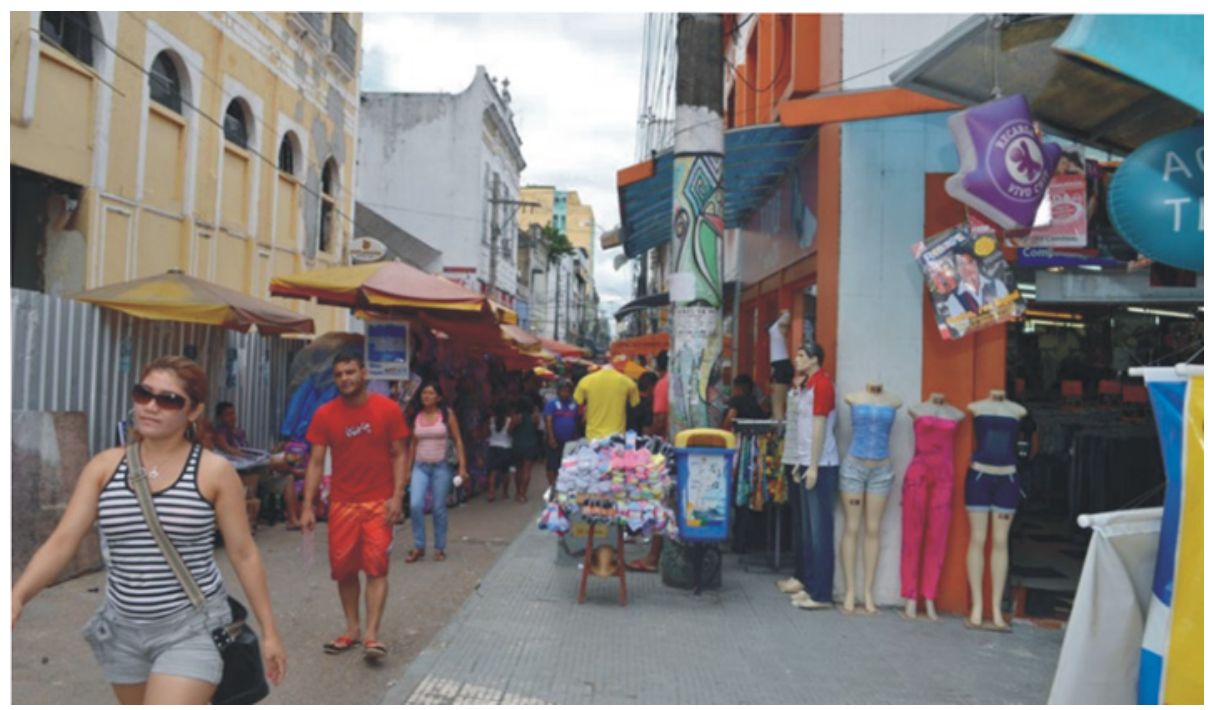

Fonte: Mobilize Brasil (2012)

Muito embora os problemas socioambientais relacionados a falta de planejamento urbano e expansão urbana acelerada pelos fluxos migratórios em Manaus sejam uma das causas do baixo percentual de arborização obtido, faz-se necessário observar que os bairros mais antigos possuem um desenho urbanístico fruto da colonização portuguesa. O modelo urbanístico europeu consistia em ruas estreitas, traçados irregulares, ausência de calçadas, construções geminadas sem recuo frontal, dificultando a introdução de vegetação de porte arbóreo (ARAGÃO, 2008; VIGNOLA JUNIOR, 2015). 


\section{INJUSTIÇA SOCIOAMBIENTAL NO ACESSO A ARBORIZAÇÃO NO BRASIL}

A análise da arborização por faixa de renda nas cidades brasileiras revelou a tendência de que quanto menor a renda média, menor é o acesso a arborização. Desta forma, os domicílios com até $1 / 4$ de salário mínimo possuem um percentual de $56,8 \%$ enquanto os domicílios com renda acima de 2 salários mínimos este percentual sobe para 78,5\%, ou seja, um aumento de quase $20 \%$ (Gráfico 3).

Gráfico 3: Percentual de arborização por faixa de renda.

\section{Percentual de arborização por faixa de renda}

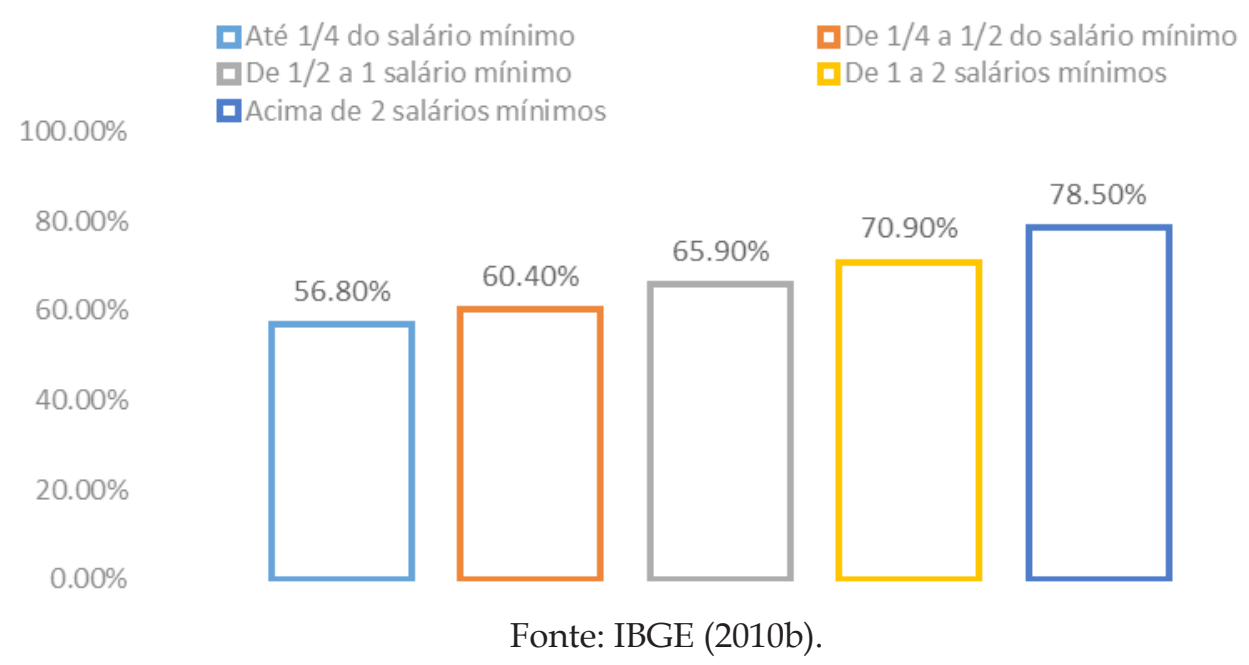

Ao analisar as condições da moradia, os resultados apontaram que nas moradias em condições consideradas adequadas, o percentual de arborização foi de $71,5 \%$, nas semi-adequadas, de 59,8\%, e nas inadequadas, 45,1\% (Gráfico 4). Portanto, quanto piores as condições de moradia, menor é o acesso a arborização.

Gráfico 4: Percentual de arborização de acordo com as condições da moradia.

\section{Percentual de arborização de acordo com as condições da moradia}

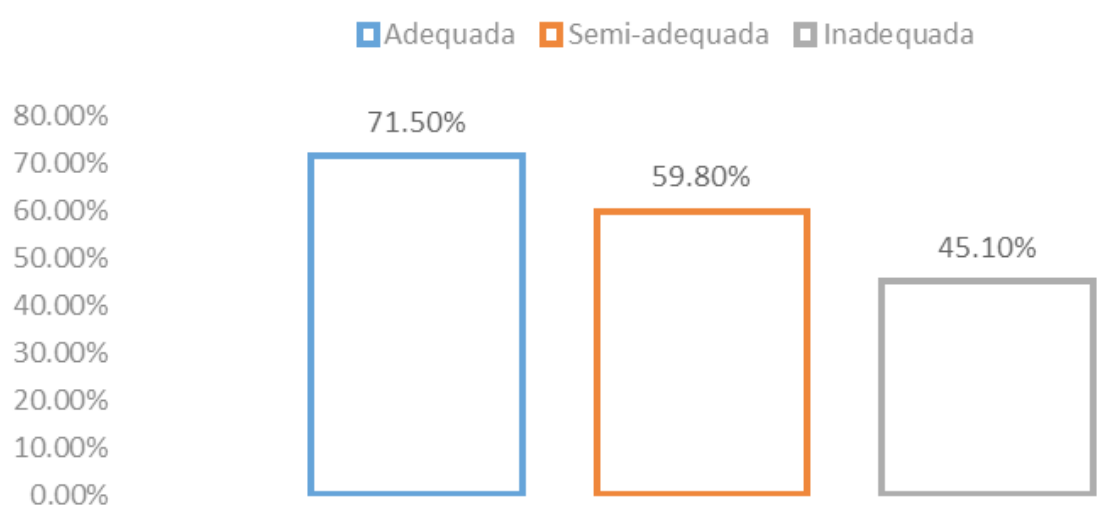

Fonte: IBGE (2010b). 
Ao sobrepor os dados relativos à arborização no entorno dos domicílios por região aos dados de incidência de extrema pobreza, também por região, disponibilizado pelo IBGE (2010a), é possível constatar que as regiões com menor incidência de extrema pobreza, conforme aponta o Gráfico 5, obtiveram os maiores percentuais de arborização no entorno do domicílio.

Gráfico 5: Incidência de extrema pobreza no Brasil por Região.

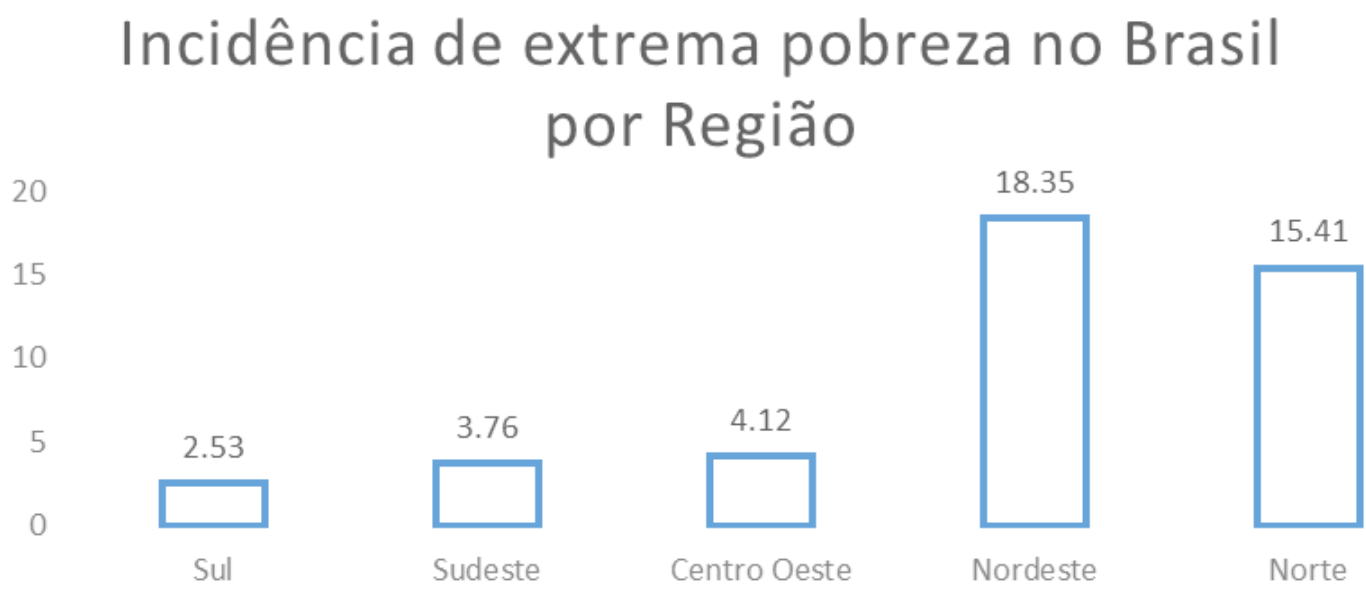

Fonte: IBGE (2010a, b).

A relação entre a incidência de extrema pobreza e arborização pode ser um reflexo da falta de infraestrutura urbana disponível às classes sociais menos favorecidas, e consequentemente um reflexo da desigualdade social no Brasil. Neste sentido, Coelho (2013), destaca que geralmente, a deterioração da qualidade ambiental de vida urbana é muito mais sentida pela população mais pobre.

A falta de infraestrutura relacionada a calçadas inadequadas, parcelamento do solo em padrões cada vez mais reduzidos, falta de planejamento urbano e ambiental são aspectos bastante sentidos pelas populações de baixa renda. Salles, Grigio e Silva (2013) observam que geralmente, as áreas de degradação ambiental nas cidades coincidem com as áreas de degradação social, ampliando seus efeitos e danos.

De acordo com o Mobilize Brasil (2012), há um contraste bastante intenso em relação infraestrutura das calçadas entre Curitiba (entre as cidades mais arborizadas do Brasil) e Salvador (em uma das regiões menos arborizadas do Brasil), como apontadas nas Figuras 2 e 3. 
Figura 2: Calçada de Curitiba - PR.

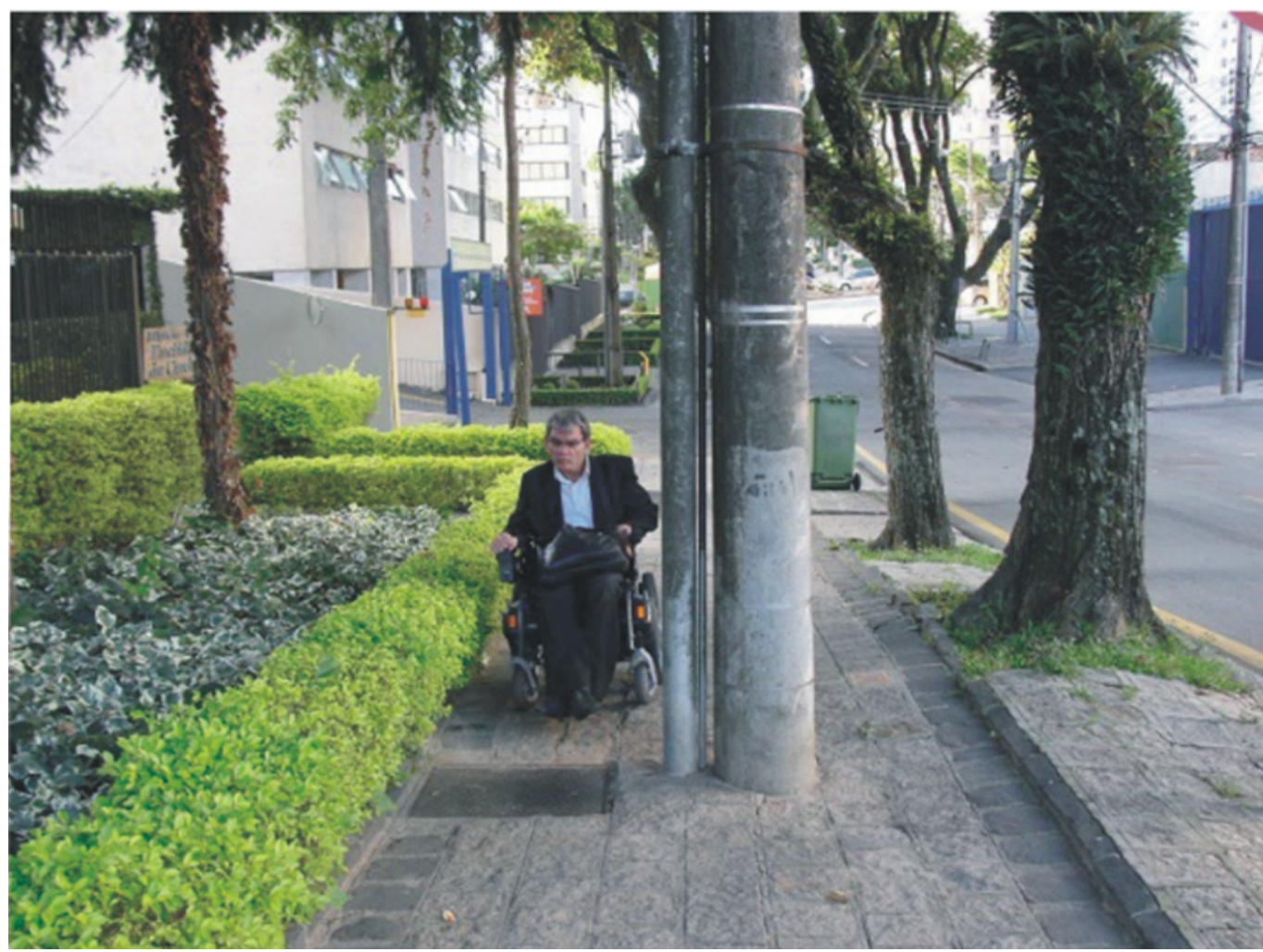

Fonte: Mobilize Brasil (2012).

Figura 3: Calçada Salvador - BA.

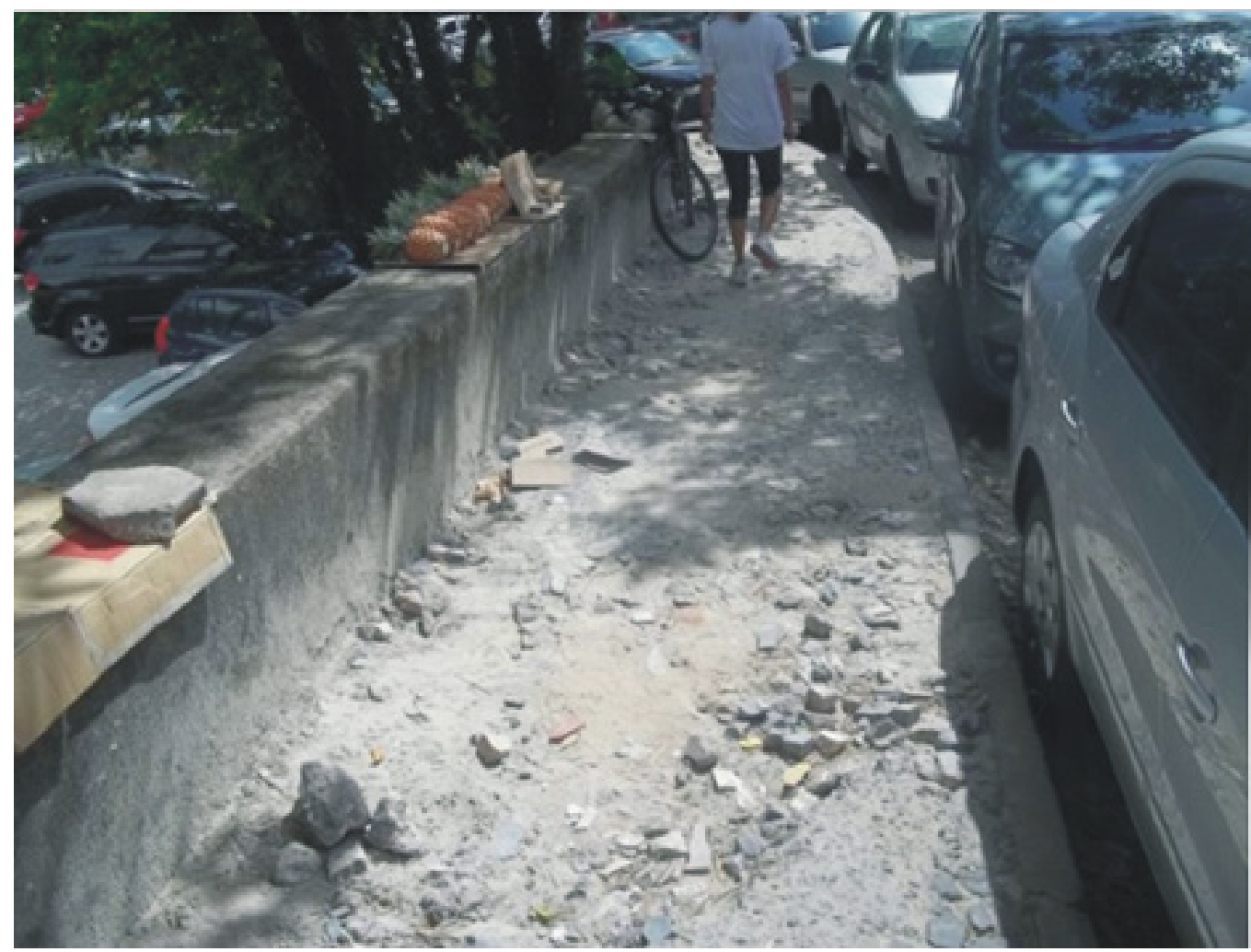

Fonte: Mobilize Brasil (2012). 
Angeoletto (2012) ao investigar a arborização urbana em um gradiente de renda na cidade de Maringá - PR, constatou que os bairros de menor renda média possuíam menor quantidade de cobertura vegetal. Dentre aspectos que interferiram na menor quantidade de cobertura vegetal nos bairros de menor renda, foi apontado os reduzidos padrões de parcelamento do solo, os quais não favorecem o plantio de árvores, destinando a população de menor renda a um menor contato com o verde no meio urbano e consequentemente, menor qualidade ambiental.

Duarte (2016) ao investigar a arborização urbana nos bairros implantados entre 2006 e 2015 em Rondonópolis - MT, apontou que os bairros mais pobres obtiveram uma baixa quantidade de cobertura vegetal, enquanto os bairros de maior renda obtiveram alta quantidade. O estudo apontou ainda que, enquanto os condomínios de alto padrão localizam-se em locais bem arborizados e próximos às áreas verdes, nos bairros mais pobres as áreas verdes se encontravam completamente degradadas.

Neste cenário, vislumbra-se que a arborização urbana tornou-se mais um, entre inúmeros elementos de segregação socioespacial no Brasil, à medida que seu acesso é proporcional à condição econômica (DUARTE, 2016).

\section{CONSIDERAÇÕES FINAIS}

A análise da arborização urbana no Brasil permitiu verificar uma relação entre infraestrutura urbana e o percentual de arborização urbana. Portanto, as ações voltadas ao incremento da arborização urbana no Brasil para melhoria da qualidade ambiental urbana devem priorizar o investimento em infraestrutura urbana planejada para a arborização.

A análise dos dados sobre a arborização urbana no Brasil, constatou que a arborização urbana tornou-se mais um elemento de segregação socioespacial. Quanto menor a renda e quanto menor as condições da moradia, menor o percentual de arborização urbana. Portanto, a arborização urbana no Brasil reflete uma situação de injustiça ambiental, que Aleixo et al. (2016) definem como uma desigualdade no acesso aos recursos ambientais. Bairros com maior status socioeconômico usualmente apresentam uma maior diversidade vegetal, seja em seus espaços livres públicos, como parques e praças (os quais usualmente inexistem em bairros pobres), seja nos seus quintais (ANGEOLETTO et al., 2015). É, logo, imperiosa a necessidade de uma partilha mais equânime da flora urbana e de seus serviços ecossistêmicos entre bairros de diferentes classes sociais, nas cidades brasileiras.

Para diminuir a diferença no acesso a arborização urbana é necessário diminuir a desigualdade social no acesso a infraestrutura urbana entre as classes sociais no Brasil. Nesse sentido, o parcelamento do solo urbano deve proporcionar condições para arborização, independentemente da classe social a que se destina.

Diante dos altos índices de crescimento urbano nas cidades médias brasileiras, bem como, nas grandes cidades da região Norte, é necessário e emergente planejar esta expansão para proporcionar maior qualidade ambiental nestes locais. Portanto, a arborização urbana é de suma importância, como forma de compensação da perda de qualidade ambiental ocorrida no processo de produção do espaço, melhorando a qualidade de vida nos espaços urbanos. 


\section{REFERÊNCIAS}

ALBUQUERQUE, M. M.; LOPES, W. G. R. Influência da vegetação em variáveis climáticas: Um estudo em bairros da cidade de Teresina, Piauí. Espaço Geográfico em Análise, Curitiba, v. 36, p. 38-68, 2016.

ALVES, D.B. Cobertura vegetal e qualidade ambiental na área urbana de Santa Maria RS. 2012 Dissertação (Mestrado em Geografia) - Universidade Federal de Santa maria, UFSM, Santa Maria - RS.

ANGEOLETTO, F. Planeta Cidade: ecologia urbana e planejamento de cidades médias do Brasil. 2012. Tese (Doutorado em Ecologia e Meio Ambiente) - Universidade Autônoma de Madrid, UAM, Madri.

. et al. El césped del vecino es más verde: Flora de patios a través de un gradiente socia. Rev. Agroneg. Meio Amb., Maringá, v. 8, p. 159-180, 2015.

. et al. Tipologia socio-ambiental de las ciudades medias de Brasil: aportes para um desarrollo urbano sostenible. Urbe - Rev. Bras. Gest. Urb., v. 8, n. 2, p. 272-287, 2016.

ARAGÃO, S. Em tempo de Histórias. Brasília: Programa de Pós-Graduação em História PPG-HIS/UnB, 2008. (n.12).

BECKER, B. K. A urbe amazônica: A floresta e a cidade. Rio de Janeiro: Garamond, 2013.

COELHO, M. C. N. Impactos ambientais em áreas urbanas: Teorias, conceitos e métodos de pesquisa. In: GUERRA, A. J. T.; CUNHA, S. B. Impactos ambientais urbanos no Brasil. 10. ed. Rio de Janeiro, Editora Anablume, 2013.

CRETELLA, A.; BUENGER, M.S. Food as creative city politics in the city of Rotterddam. Cities, v. 51, p. 1-10, 2016.

CUBINO, J.P.; LOZANO, C.B.; SUBIRÓS, J.V. Plant biodiversity and city: Approaches fron urban ecology.

Bol. Asoc. Geógr. Esp., v. 18, p. 465-471, 2015.

CURADO, MMC. O grafite como instrumento de requalificação dos espaços públicos: o caso das praças de fundo de quadra no setor sul, Goiânia. In: COLÓQUIO IBERO AMERICANO PAISAGEM CULTURAL, PATRIMÔNIO E PROJETO - DESAFIOS E PERSPECTIVAS. 3, 2014, Belo Horizonte.

DUARTE, T.E.P.N. Expansão urbana e qualidade ambiental: uma análise da cobertura vegetal urbana em Rondonópolis entre os anos de 2006 e 2015. 2016. Dissertação (Mestrado em Geografia) - Universidade Federal de Mato Grosso, UFMT. Rondonópolis - MT.

DUARTE, F. G. et al. Cupins (Insecta: Isoptera) na arborização urbana da Zona 1 de Maringá - PR. Rev. Agroneg. Meio Amb., Maringá, v. 1, n. 1, p. 87-99, 2008.

EMBRAPA. Arborização urbana e produção de mudas de essências florestais nativas em Corumbá, MS. Corumbá, 2002.

IBGE. INSTITUTO BRASILEIRO DE GEOGRAFIA E ESTATÍSTICA. Censo 2010. Rio de Janeiro, 2010a. Disponível em: <http:/ / cidades.ibge.gov.br/xtras/perfil.php?codmun=150140>. Acesso em: 15 out. 2016.

Características urbanísticas do entorno dos domicílios. Rio de Janeiro, 2010b. p. 1-175.

IPEA. INSTITUTO DE PESQUISA ECONÔMICA APLICADA. População e PIB das cidades médias crescem mais que no resto do Brasil. Brasília, 2008.

LOCKE, D.H. et al. Applications of urban tree canopy assessment and prioritizations tools: Supporting collaborative decisions making to achieve urban sustainability goals. Urb. Forest. Pract., v. 6, p. 1-26, 2013.

LOURENÇO, F.A. et al. Metrópolis, cobertura vegetal, áreas verdes e saúde. Estudos Avançados, v. 30, p. 113-130, 2016.

MARICATO, E. Cidades: alternativas para a crise urbana. 5. ed. Petrópolis: Vozes , 2011. 
MOBILIZE BRASIL. Campanha Calçadas do Brasil. 2012. Disponível em: <mobilize.org.br>. Acesso em: 20 nov. 2016.

NUCCI, J. C.; CAVALHEIRO, F. Cobertura vegetal em áreas urbanas - conceito e método. Geo USP, São Paulo, v. 6, p. 29-36, 1999.

PADOCH, C. et al. Urban forest and rural cities: multi-sited households, consumption patterns, and forest resources in Amazonia. Ecol. Soc., v.13, n. 2, 2008.

PEREIRA, F.S.; VIEIRA, I.C.G. Expansão urbana da Região Metropolitana de Belém sob a ótica de um sistema de índices de sustentabilidade. Rev Amb. \& Água, v.11, n.3, p. 731-744, 2016.

PREFEITURA MUNICIPAL DE FORTALEZA. Plano de Arborização. 2015. Disponível em: <https:// urbanismoemeioambiente.fortaleza.ce.gov.br/images/urbanismo-e-meio-ambiente/infocidade/ resultados_plano_de_arborizacao_2015.pdf >. Acesso em: 06 jan. 2017.

RAHMAN, M. A.; ARMSON, D.; ENNOS, A. R. A comparison of the growth and cooling effectiveness of five commonly planted urban tree species. Urb. Ecosyst., v. 18, p. 371-389, 2014.

RICHARD, E., CONTRERAS, Z.D.; ANGEOLETTO, F. Influencia, servicios y funciones terapéuticas, psicológicas, ambientales, biofílicas, de bienestar y vivir bien de los espacios verdes urbanos en el urbanita, instituciones educativas, hospitales, centros de salud e instituciones similares. Revista Médica de la Univ. Pública de El Alto, 2017 (no prelo).

SALLES, M.C.T.; GRIGIO, A.M.; SILVA, M.R.F. Expansão urbana e conflito ambiental: uma descrição da problemática do município de Mossoró, RN - Brasil. Soc. \& Nat., Uberlândia, v. 25, n. 2, p. 281-290, 2013.

SAMPAIO, A.C. Análise da arborização de vias públicas das principais zonas do plano piloto de Maringá - PR. 2006 Dissertação (Mestrado em Geografia) - Universidade Estadual de Mariná, UEM, Maringá - PR.

SECRETARIAT OF THE CONVENTION ON BIOLOGICAL DIVERSITY. Panorama da biodiversidade. Montreal: Cities and Biodiversity Outlook, 2012.

SILVA, M. C. Arborização urbana de quatro cidades do leste de Mato Grosso do Sul. 2013. Dissertação (Mestrado em Geografia) - Universidade Federal de Goiás, UFGO, Jataí - GO.

TIAN, Y.; TAO, Y.; SHI, T. Landscape ecological assessment of green space fragmentation in Hong Kong. Urb. Forest. \& Urb. Green., v. 10, p. 79-86, 2011.

VIGNOLA JUNIOR, R. ArbVias - Método de avaliação da arborização no sistema viário urbano. Paisagem e Ambiente. v.1, n. 35 p.89-117 São Paulo, 2015.

Data de submissão: 27/02/2017

Data de aceite: 10/11/2017 